\title{
DESIGN AND EVALUATION OF A COCKPIT DISPLAY \\ FOR HOVERING FLIGHT
}

\author{
Ronald A. Hess ${ }^{1}$ and Peter James Gorder ${ }^{2}$ \\ Department of Mechanical Engineering \\ University of California, Davis
}

Abstract

A simulator evaluation of a cockpit display format for hovering flight is described. The display format is based upon the position-velocity-acceleration representation (PVA) similar to that used in the Pilot Night Vision System in the Army AH-64 helicopter. By only varying the nature of the display law driving the "primary" indicator in the PVA format, i.e. the acceleration symbol, three candidate displays are created and evaluated. These range from a Status display in which the primary indicator provides true acceleration information to a Command display, in which the primary indicator provides flight director information. Simulation results indicate that two of the three displays offer performance and handling qualities which make them excellent candidates for future helicopter cockpit display systems.

\footnotetext{
${ }^{2}$ Professor, Associate Fellow AIAA

${ }^{2}$ Graduate Student, Member AIAA
} 


\section{Introduction}

The pilots of advanced rotorcraft are being asked to perform increasingly difficult tasks in conditions in which visual out-the-window cues are very poor or nonexistent. Hover and low-speed maneuvering have long been recognized as one of the most workload intensive of such tasks. To aid the pilot in these situations, advanced control and display concepts are being evaluated and utilized [1]. The objective of the study to be described is the modification and evaluation of an existing display format with the goal of improving vehicle handling qualities in a demanding hover task. The display format selected was one currently in operational use in the Army AH-64 Apache attack helicopter. This format is incorporated in a system, called the pilot Night Vision system (PNVS), and is superimposed on a forward-looking infrared (FLIR) image and presented to the pilot on a helmet-mounted display [2].

The general format of the PNVS display is shown in Fig. 1 . It utilizes a position-velocity-acceleration (PVA) format in the longitudinal and lateral axes in that distinct symbols on the display present longitudinal and lateral vehicle position (hover pad symbol), vehicle velocity (velocity vector), and a lead indicator for the vehicle velocity (acceleration). The latter symbol in this study will be referred to as a "primary" indicator, and the display laws which drive it varied from the simple status information provided by vehicle acceleration to a combination of vehicle response variables. This combination is obtained via a pilot/vehicle analysis to be described. The resulting display laws are then incorporated in the display of Fig. 1, implemented in a head-up (but not helmet mounted) display and evaluated in manned fixed-base simulation. 
A plethora of display/control system configurations have been investigated to determine their effectiveness in rotorcraft low-speed flight tasks under Instrument Meteorological conditions [3]. These studies include the variation of display medium, format, and dynamics with different stability and control augmentation systems. The basic PVA display format used here was evaluated recently in a study conducted at NASA Ames Research Center [4]. In Ref. 4, the display medium was a panel-mounted cathode ray tube (CRT) display in the NASA/Army $\mathrm{CH}-47 \mathrm{~B}$ variable stability helicopter. The purpose of the study was to investigate the effects of compatible and incompatible display and control system response characteristics, and to evaluate a candidate display law design methodology. It is the latter goal which relates directly to the motivation behind this study. The display described in Ref. 4 as the "PNVS" display were used as a benchmark for the candidate display law designs presented herein, and the manned simulation experiment was designed to maintain consistency with this previous study wherever possible.

\section{Control/Display Laws}

Three different display systems differing in the display laws driving the primary indicator were designed and evaluated. They are referred to as: 1.) the Status display, 2.) the Predictor display, and 3.) the Command display. Finally, as just noted, the PNVS display, as evaluated in Ref. 4 was used as a benchmark. This display is referred to as the command-status display herein. All of these display types were designed to be flown by the pilot in a similar manner: The pilot moves the cyclic control to drive the "primary indicator" into the hover pad symbol. Thus, the intent of the display designs was to relieve the pilot of the workload associated with the instrument scanning and 
information integration which normally accompanies hovering flight under Instrument Meteorological Conditions.

In the status display, the primary indicator is a representation of the rotorcraft's inertial acceleration. In the Predictor display, the primary indicator represents a prediction of the position of the tip of the vehicle velocity vector $\tau_{\infty}$ seconds into the future. In the Command display, the primary indicator is essentially a flight director signal, not referenced to the end of the velocity vector. It represents an error in control input which the pilot attempts to null with control motion and can be referenced to the center of the display or the hover pad symbol. As just mentioned, the indicator was referenced to the hover pad symbol in this study.

Three different vehicle response types were investigated: 1.) An angular rate-command/attitude hold system (RATE), 2.) an attitude-command/attitude hold system (ATTITUDE), and 3.) a velocity-command/attitude-hold system (VELOCITY). The dynamics of these systems are identical to those evaluated in Ref. 4 and were created by the simple state feedback design shown in Fig. 2. Note the simplified attitude dynamics of the unaugmented vehicle. Table 1 lists the values of the variables shown in Fig. 1 which create the RATE, ATTITUDE and VELOCITY control systems, while Table 2 shows the vehicle attitude to control transfer functions resulting from each of these feedback implementations. It was these latter control/response dynamic characteristics of Table 2 which were implemented on the model-following flight control system of the variable stability rotorcraft of Ref. 4 to yield the three fundamental response types just mentioned. 


\section{Simulation Tasks}

The tasks undertaken in the manned simulation to be described were also identical to those of Ref. 4. Each combination of control/display type is referred to as a "configuration" and each configuration was evaluated in two tasks. The first was a "pad capture" task. Here, the hover pad symbol would undergo an initial step displacement from the center of the display to a new position corresponding to a $60 \mathrm{ft}$ movement of the desired hover point. The pilot was required to fly the vehicle to a stable hover over the new hover point. This represented a standard precision hover task which emphasized tight control of vehicle position. The second task was a "pad tracking" task in which the hover pad symbol was driven by a sum of sinusoids and the pilot was required to attempt to keep the vehicle over the moving pad. This task can be thought of as tracking a moving ground target or hovering in the presence of atmospheric turbulence. The sums of sinusoids are shown in Table 3 , and again, are identical to those used in Ref. 4.

\section{Display Law Designs}

\section{The PVA Format}

Since the PVA display format provides the fundamental display layout for all the displays studied herein, a brief description of the design philosophy behind this format is in order. In the PVA display, the primary indicator can be referred to as an acceleration symbol which is referenced to the end of the velocity vector symbol. Thus, if the vehicle were traveling at a constant velocity, its inertial acceleration would be zero and the acceleration symbol would be positioned on the tip of the velocity vector. The equations governing : the position of the acceleration symbol are 


$$
\begin{aligned}
& A_{x}=K_{e c}(\dot{x}+\ddot{x}) \\
& A_{y}=K_{e c}(\dot{y}+\ddot{y})
\end{aligned}
$$

Figure $3 a$ is a graphical representation of Eqs. 1 in terms of actual display format.

The position of the hover pad symbol on the display is determined by the distance between the vehicle and the desired hover point. The vehicle position is always represented by the center of the screen in a "heading-up" mode. The appropriate equations are simply

$$
\begin{aligned}
& H_{x}=K_{h v}\left(x_{c}-x\right) \\
& H_{y}=K_{h v}\left(y_{c}-y\right)
\end{aligned}
$$

where $K_{\text {nv }}$ is a display scale facor. Figure $3 b$ is a graphical representation of Eqs. 2 in terms of display format.

Now consider the vehicle at some initial displacement from a fixed hover pad location, as indicated in Fig. $3 b$. The piloting strategy of placing and maintaining the acceleration symbol on the hover pad symbol is equivalent to $A_{x}=H_{x}$ and $A_{y}=H_{y}$ in Eqs. 1 and 2. Considering the solution to the resulting coupled linear differential equations to unit step inputs $x_{c}$ and $y_{c} y i e l d s$ the following expressions for vehicle position errors as a function of time: 


$$
x_{-}(t)=y_{-}(t)=[b /(b-a)] \exp (-a t)+[a /(b-a)] \exp (-b t)
$$

where

$$
\begin{aligned}
& a=\left\{1-\left[1-\left(4 K_{h v} / K_{-c}\right)\right]^{0.5}\right\} / 2 \\
& b=\left\{1+\left[1-\left(4 k_{\text {hv }} / K_{=c}\right)\right]^{0.3}\right\} / 2
\end{aligned}
$$

Thus, the pilating strategy based upon keeping the acceleration symbol on the hover pad symbol would result in an exponential approach to the desired stationary hover position.

In the case of a moving pad, the strategy just described would result in a steady state vehicle position error if the pad were translating at constant velocity. The pilot could correct for this by first coming to a steady state position offset by placing the acceleration symbol on the hover pad symbol, and then move the acceleration symbol slowly beyond the pad in order to compensate for the error. Thus, a viable initial strategy for capturing a hover point which is either stationary or steadily translating in inertial space is to place the acceleration symbol on the hover pad symbol and maintain it in that position.

\section{The Status Design}

The status display is identical to the PVA display just described. Since the task required of the pilot is to place the acceleration symbol on the hover pad symbol and keep it there, the ability of the pilot to accurately control the acceleration symbol is of paramount importance. It is pertinent, 
therefore, to investigate the relationship between acceleration symbol motion and control inputs. These can be summarized as

$$
\begin{aligned}
& A_{x} / \sigma_{=}=\left[-g(s+1) /\left(s-X_{u}\right)\right]\left[\theta / \sigma_{e}\right] \\
& A_{y} / \delta_{z}=\left[g(s+1) /\left(s-Y_{v}\right)\right]\left[\phi / \delta_{n}\right]
\end{aligned}
$$

The Bode diagram for $A_{x} / \sigma_{2}$ is shown in Fig. 4 for the three control systems studied. Since the crossover frequencies for these tasks are likely to be above $1 \mathrm{rad} / \mathrm{sec}$, the required pilot compensation as predicted by the crossover model of the human pilot [5], will be lead generation, with a lead time constant greater than $1 \mathrm{sec}$. Such lead equalization means increased pilot workload. Similar results hold for the lateral case which will not be discussed here. Thus, while the strategy of keeping the acceleration symbol on he hover pad is sound, the piloting task of doing so with the status display will be difficult.

\section{The Predictor Design}

With the predictor display, the primary indicator provides a prediction of the position of the tip of the velocity vector on the vehicle $\tau_{p}$ seconds in the future. A three term Taylor series approximation to $\dot{x}\left(t+\tau_{p}\right)$ was utilized which resulted in the following primary indicator dynamics for a prediction time constant of $1 \mathrm{sec}$ :

$$
A_{x}=K_{s=c}\left\{\dot{x}+\tau_{p} \ddot{x}-\left[g\left(\tau_{p}\right)^{2} \ddot{\theta} /\left(2\left(s-X_{x}\right)\right)\right]\right\}
$$




$$
\begin{aligned}
& A_{Y}=K_{=c}\left\{\dot{y}+\tau_{p} \ddot{y}+\left[g\left(\tau_{p}\right)^{2} \ddot{\phi} /\left(2\left(s-Y_{v}\right)\right)\right]\right\} \\
& A_{x} / \delta_{-}=\left[-g\left(0.5 s^{2}+s+1\right) /\left(s-X_{u}\right)\right]\left[\theta / \sigma_{e}\right] \\
& A_{y} / \delta_{E}=\left[g\left(0.5 s^{2}+s+1\right) /\left(s-Y_{v}\right)\right]\left[\phi / \sigma_{-}\right]
\end{aligned}
$$

The Bode diagram for $A_{x} / \sigma_{2}$ is shown in Fig. 5 for the three control systems studied. In terms of the required pilot equalization, things are improved considerably over the status display as only pure gain equalization is required of the pilot for crossover frequencies above $1.0 \mathrm{rad} / \mathrm{sec}$. Indeed, the prediction time constant of $1 \mathrm{sec}$ was chosen so as to create this desirable chas acteristic.

The Command Display

The Command display differs from the Status and Predictor displays, in ... that it is based upon a flight-director design philosophy. As exercised here, the Command display law for the primary indicator was obtained by considering the control strategy which the pilot would use in the pad tracking task and then providing a cyclic command through the acceleration symbol on the display which is based upon this strategy. This general flight director design approach is discussed in Ref. 6.

Consider Fig. 6 which is a block diagram representation of the loop closures which a pilot would employ in controlling the longitudinal position of the vehicle under consideration without the aid of a special display. A similar diagram could be drawn for the lateral mode. Here, three loops are 
closed involving the control of vehicle attitude, velocity and position, respectively. The hypothesis here is that, for the purposes of command display design, the loop closure sequence shown in Fig. 6 would be utilized by the pilot for all the vehicle response types studied herein including the velocity command system. This is a somewhat unorthodox approach since the usual assumption (e.g., Ref. 7) is that the pilot does not have to close an attitude loop with a velocity command system. However, this approach prevents what might be a poor velocity command system from adversely affecting the command display design.

Each loop closure in Fig. 6 is modeled by an application of the crossover model of the human pilot, with crossover frequencies differing by a factor of 2 between loops. While a factor of $3-4$ is usually assumed in multiloop modeling problems, e.g., Ref. 6, the factor of 2 was chosen to provide a command display suited to the demands of the pad tracking task. In single axis laboratory tracking tasks, crossover frequencies on the order of 3-5 rad/sec are typical, depending upon the controlled element dynamics and the input bandwidth [5]. Because this experiment was multi-axis in nature, a nominal attitude loop crossover frequency of $2 \mathrm{rad} / \mathrm{sec}$ was chosen. The crossover frequencies in the velocity and position loops then become, 1 and $0.5 \mathrm{rad} / \mathrm{sec}$ respectively.

As Table 2 indicates, the attitude to control transfer functions for all the response types were second order in the region of crossover. The pilot model for the command display design was thus chosen of the form $Y_{D}=K_{D}(T s+1)$. The lead time constant $T$ was chosen to force $K / s-l i k e$ amplitude characteristics in the open-loop pilot/vehicle transfer function 
around crossover and $\mathrm{K}_{\mathrm{p}}$ was chosen to give the desired crossover frequency. Because the subsequent control loops for both the longitudinal and lateral cases involved effective controlled element dynamics which are $\mathrm{K} / \mathrm{s}-1 \mathrm{ike}$ around the respective outer loop crossover frequencies, the pilot transfer functions for these closures are pure gains $K_{x}$ and $K_{x}$, selected to give the desired crossover frequencies.

Using Fig, 6 and a similar diagram for lateral control, the following expressions for the pilot control inputs result:

$$
\begin{aligned}
& \delta e_{c}=K_{\dot{x}} R_{x} Y_{p}\left(x_{c}-x\right)-K_{\dot{x}} Y_{p} \dot{x}-\left(Y_{p} \theta_{w 0}\right) \\
& \delta a_{c}=K_{\dot{y}} K_{y} Y_{p}\left(y_{c}-y\right)-K_{\dot{y}} Y_{p} \dot{y}-\left(Y_{p} \phi_{w o}\right)
\end{aligned}
$$

The similarity between the longitudinal and lateral attitude dynamics allowed a.. inner-loop pilot dynamics $Y_{p}$ which differed only in the gain $K_{p}$ to be used for the two axes for each response type. $\theta_{\text {wo }}$ and $\phi_{\text {wo }}$ refer to pitch and rollattitude passed through a first order washout filter with a 20 sec time constant.

The Command display can now be created by simply implementing Eqs. 7 as a display law, and driving the primary indicator by variables $A_{x}$ and $A_{y}$, which are now nothing more than $6 \mathrm{e}_{c}$ and $\delta \mathrm{a}_{c}$, appropriately scaled. Thus, the position of the primary indicator relative to some null position on the display screen provides longitudinal and lateral cyclic commands to the pilot for the task at hand. In order to provide a common control strategy across the 
different display types, the null position for the primary indicator for the Command display was chosen as the hover pad symbol, itself. In addition, the scaling of the primary indicator had to be chosen so that the instantaneous pad displacement at the beginning of the pad capture task did not cause primary indicator movement. This was accomplished using the same scaling the primary indicator as for the hover pad symbol for pure position error.

The primary indicator dynamics for the Command display can be given as:

$$
\begin{aligned}
& A_{x}=K_{\bmod }\left\{K_{m x}\left[K_{D x}\{s+(1 / T))\left(-K_{x} K_{\dot{x}} x-K_{\dot{x}} \dot{x}-\theta_{w o}\right)\right]-H_{x}\right\} \\
& A_{y}=K_{m o d}\left\{K_{x y}\left[K_{p y}(s+(1 / T))\left(-K_{y} K_{y} y-K_{y} \dot{y}-\phi_{w_{0}}\right)\right]-H_{y}\right\} \\
& A_{x} / \delta_{e}=\left\{K _ { p x } [ s + ( 1 / T ) ] \left[s^{3}-\left(X_{u}+g K_{x}^{*}\right) s^{2}-\right.\right. \\
& \left.\left.\operatorname{gK}_{x} \cdot\left(\left(1 / \tau_{w_{0}}\right)+K_{x}\right) s-\left(g K_{x} \cdot K_{x}\right) / \tau_{w 0}\right]\right\} /\left\{s(s-X u)\left(s+1 / \tau_{w 0}\right)\right] \\
& A_{y} / \sigma_{z}=\left\{K _ { p y } [ s + ( 1 / T ) ] \left[s^{3}+\left(-Y_{v}+g K_{y}^{p}\right) s^{2}+\right.\right. \\
& \left.\left.\operatorname{gK}_{\dot{y}}\left(\left(1 / \tau_{w_{0}}\right)+K_{y}\right) s+\left({g K_{y}}_{j} K_{y}\right) / \tau_{w_{0}}\right]\right\} /\left[s\left(s-Y_{v}\right)\left(s+1 / \tau_{w_{0}}\right)\right]
\end{aligned}
$$

Here, $\tau_{\text {wo }}$ is the $20 \mathrm{sec}$ attitude washout time constant just mentioned. The Bode diagram for the $A_{x} / 6$ e transfer functions are shown in Fig. 7 for each of the control response types. Note the desirable $\mathrm{K} / \mathrm{s}-1$ ike characteristics.

\section{The Command-Status Display}

The philosophy behind the Command-Status design is discussed in Ref. 4 and will not be treated here. Like the Command display, it is based upon a flight 
director concept, but with different primary indicator dynamics. The Bode diagram for the $A_{x} / \sigma_{e}$ transfer functions are shown in Fig. 8 for each of the control response types. Note that, as compared to the diagrams of Fig. 7, the Command-Status display dynamics are not $\mathrm{K} / \mathrm{s}-1 \mathrm{ike}$ in the region of inner loop crossover. The flat amplitude characteristics for frequencies beyond $1 \mathrm{rad} / \mathrm{sec}$ indicate that the pilot would have to generate lag equalization for crossover frequencies above $1 \mathrm{rad} / \mathrm{sec}$.

Figures 9 and 10 list the parameter values for Eqs. 7 and 8 in addition to the display scaling constant $\mathrm{K}_{\text {ec }}$ for each display and control response type. The degrees appearing in the numerator of the units for the constant $\mathrm{K}_{\text {ac }}$ are "screen" degrets, a unit peculiar to the particular display implementation.

\section{$\underline{\text { Simulation }}$}

The experimental matrix for the manned simulation possessed twenty-four elements consisting of four display types and three control response types for each of the two tasks involved. A NASA Ames fixed-base simulator, referred to as Chair 6, was utilized in the experimental study. The simulator has a computer generated terrain image, visible on a $2{ }^{\prime} \times 2$ ' window in the cockpit. The head-up display symbology of Fig. 1 was projected onto this window using a half silvered mirror. Both the terrain image and display are focused at infinity. Four NASA test pilots were used in the simulation.

In each of the tasks, criteria of desired and adequate performance were communicated to the pilots: 
(1) Pad capture task

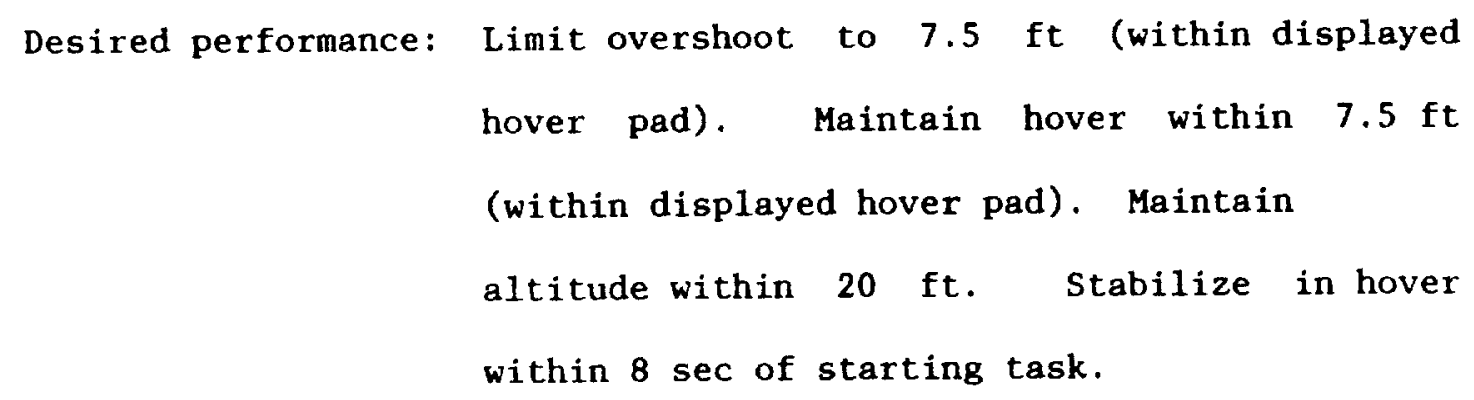

Adequate Performance: Twice the values for desired performance.

(2) Pad tracking task

Desired performance: Maintain position relative to hover pad to within $7.5 \mathrm{ft}$. Maintain altitude within $10 \mathrm{ft}$ Maintain heading with 5 deg.

Adequate performance: Twice the values for desired performance.

Two different types of simulation sessions were organized for each of the pilots. The first was a performance session, the second a handing qualities rating (HQR) session. In the latter, the Cooper-Harper pilot rating scale was utilized [8]. In presenting the configurations to each pilot, no two consecutive configurations were presented with the same display type or control system response type. Three different schedules of such presentations were created. In the performance session, each configuration was run four times in succession. The first three runs were pad capture tasks with the last being a 
two minute pad tracking task. In the pad capture task, the pad was displaced first in the $x$ direction (vertically on the display), then the $y$ direction (horizontally to the right on the display), then in a random azimuth direction. In all, three sets of such performance runs were required of each pilot. Although four pilots were used in the simulation, only three were able to contribute full data sets which consisted of three performance sessions and one ratings session. The fourth pilot completed only one data taking session, but did complete the rating session.

\section{$\underline{\text { Results }}$}

Figures 11-15 summarize the performance data for the pad tracking task and the handling qualities data for both the pad tracking and pad capture tasks across display control laws and control response types. For the sake of brevity, only performance data for longitudinal control in the pad tracking task is presented. Of particular interest here are the shaded symbols. The initial Command display was rated rather poorly and pilot comments indicated that the pilots objected to the large attitude excursions which accompanied Command display use. The shaded symbols represent performance and ratings for the Command display with a modified null position which was on an imaginary line through the center of the display and the hover pad symbol but at twice the distance of the pad from the screen center. The location of the new null position was unknown to the pilot, and of no consequence in the tasks. The pilot was still instructed to place the primary indicator on the pad symbol and simply noticed that smaller control inputs and vehicle attitudes were required in order to accomplish this than previously. A single pilot was used to evaluate the modified Command display. As can be seen from the figures, the 
modified Command display resulted in a significant improvement in performance and ratings.

While Figs. 11-15 tend to speak for the themselves, three results clearly stand out: Namely, for the tasks studied here (1) the Predictor and Command designs emerge as superior display candidates, (2) the RATE response system does not offers adequate stability and control augmentation, and (3) as the control response type increases in sophistication, performance and ratings are less dependent upon display type. This result is consistent with the results of past research on control/display tradeoffs, e.g., Ref. 3.

Figure 16 compares the ratings obtained with the Command-Status display of this experiment with those obtained from the equivalent PNVS display in flight and reported in Ref. 4. The comparisons are seen to be excellent. This is particularly noteworthy given the limitations of the fixed base simulator. This excellent comparison is probably due to three factors: First, the vehicle dynamics simulated both in the laboratory and in flight were relatively simple in form, as was the control augmentation used to obtain the response types. Second, the flight task used a head-down display so that visual field cues were not utilized in flight. Finally, the task itself was well-defined and centered upon use of the primary indicator in the cockpit displays.

\section{Conclusions}

Based upon the analytical and experimental study summarized herein, the following specific conclusions can be drawn.

1.) The Predictor and Command displays offer excellent performance and 
handling qualities in both the pad tracking and capture tasks. Both displays should be serious candidates for inclusion in future helicopter cockpit display systems.

2.) The effect of the scaling of the primary indicator is very important and should be taking into account in the design process. When superior display dynamics are coupled with poor scaling, both pilot opinion and performance suffer considerably.

3.) With increased vehicle control augmentation, the dynamics of the primary indicator become less critical. This is due to the decrease in pilot workload brought about by the higher levels of augmentation.

\section{Acknowledgement}

This work was performed under grant No. NCC2-383, NASA Ames Research Center. The advice and assistance of Mr. Edwin Aiken and Dr. J. Victor Lebacqz of the Flight Dynamics and Controls Branch is deeply appreciated. 


\section{References}

[1] Aiken, E. W, and Merrill, R. K., "Results of a Simulator Investigation of Control System and Display Variations for an Attack Helicopter Mission," AHS Preprint No. 80-28; American Helicopter Society 36th Annual National Forum, Washington, D.C., May, 1980 .

[2] Tsoubanos, C. M., and Relley, M. B., "Pilot Night Vision System (PNVS) for Advanced Attack Helicopter (AAH)," American Helicopter Society 34 th Annual National Forum, Washington, D. C., May 1978.

[3] Lebacqz, J. V., "Survey of Helicopter Control/Display Investigations for Instrument Decelerating Approach," NASA TM 78565, 1979.

[4] Eshow, M. M., Aiken, E. W., and Hindson, W. S., "Preliminary Results of a Flight Investigation of Rotorcraft Control and Display Laws for Hover," American Helicopter Society Mideast Regional National Specialists' Meeting in Rotorcraft Flight Controls and Avionics, Oct. 13-15, 1987, Cherry Hill, New Jersey .

[5] McRuer, D. T., and Krendel, E. S., "Mathematical Models of Human Pilot Behavior," AGARDograph No. 188, Jan. 1974.

[6] Hess, R. A., and McNally, B. D., "Automation Effects in a Multiloop Manual Contro1 System," IEEE Transactions on Systems, Man, and Cybernetics, Vol. SMC-16, No. 1, Jan./Feb. 1986, pp. 111-121. 
[7] Hoh, R. H., and Ashkenas, I. L., "Effect of Reduced Visibility on VTOL Handling Quality and Display Requirments," Journal of Guidance and Control, Vo1. 4, No. 2, March/April 1981, pp. 171-176.

[8] Cooper G. E. and Harper, R. P., Jr., "The Use of Pilot Rating in the Evaluation of Aircraft Handling Qualities," NASA TN-D-5133, April, 1969. 


\section{Figure Captions}

Figure 1. The position-velocity-acceleration (PVA) display format.

Figure 2. Control augmentation for the three control response types.

Figure 3. Display variable definitions.

Figure 4. Primary indicator dynamics for the status display, longitudinal control.

Figure 5. Primary indicator dynamics for the Predictor display, longitudinal control.

Figure 6. Pilot loop closures in a hover task.

Figure 7. Primary indicator dynamics for the Command display, longitudinal control.

Figure 8. Primary indicator dynamics for the Command-Status display, longitudinal control.

Figure 9. Display law parameter values, Status and Predictor displays.

Figure 10. Display law parameter values, Command display.

Figure 11. Pilot/vehicle performance, primary indicator error.

Figure 12. Pilot/vehicle performance, longitudinal cyclic input.

Figure 13. Pilot/vehicle performance, longitudinal position error.

Figure 14. Cooper-Harper ratings, pad capture task.

Figure 15. Cooper-Harper ratings, pad tracking task.

Figure 16. Pilot rating comparison, simulation vs. flight test. 
Table 1. Control System Parameters.

\begin{tabular}{|c|c|c|c|}
\hline & RATE & ATTITUDE & VELOCITY * \\
\hline$M_{u}$ & $0 \mathrm{rad} / \mathrm{ft} \cdot \mathrm{sec}$ & $0 \mathrm{rad} / \mathrm{ft} \cdot \mathrm{sec}$ & $0.0152 \mathrm{rad} / \mathrm{ft} \cdot \mathrm{sec}$ \\
\hline$M_{q}$ & $-2.01 / \mathrm{sec}$ & $-2.0 \quad 1 / \mathrm{sec}$ & $-3.0881 / \mathrm{sec}$ \\
\hline$M_{8}$ & $0 \quad 1 / \sec ^{2}$ & $-2.0 \quad 1 / \sec ^{2}$ & $-2.7251 / \sec ^{2}$ \\
\hline$M_{\delta_{e}}$ & $0.21 \quad 1 /$ in.sec 2 & $0.28 \quad 1 /$ in $\cdot \sec ^{2}$ & $0.271 /$ in $\cdot$ sec $^{2}$ \\
\hline$x_{u}$ & $-0.041 / \mathrm{sec}$ & $-0.041 / \mathrm{sec}$ & $-0.041 /$ sec \\
\hline$L_{v}$ & $0 \mathrm{rad} / \mathrm{ft} \cdot \mathrm{sec}$ & $0 \mathrm{rad} / \mathrm{ft} \cdot \mathrm{sec}$ & $-0.0198 \mathrm{rad} / \mathrm{ft} \cdot \mathrm{sec}$ \\
\hline$L_{p}$ & $-2.01 / \mathrm{sec}$ & $-2.01 / \mathrm{sec}$ & $-3.2081 / \mathrm{sec}$ \\
\hline$L_{\phi}$ & $0 \quad 1 / \sec ^{2}$ & $-2.01 / \sec ^{2}$ & $-3.0291 / \sec ^{2}$ \\
\hline$L_{\delta_{\theta}}$ & $0.211 /$ in $\sec ^{2}$ & $0.28 \quad 1 /$ in $\cdot \sec ^{2}$ & $0.44 \quad 1 /$ in $\cdot \sec ^{2}$ \\
\hline$Y_{v}$ & $-0.121 / \mathrm{sec}$ & $-0.121 / \sec$ & $-0.121 / \mathrm{sec}$ \\
\hline
\end{tabular}

*The parameters listed lead to the following transfer function coefficients in Table 2:

$\begin{array}{rccc} & \tau_{v} & \zeta_{v} & \omega_{v} \\ \text { londitudinal } & 3.33 & 1.0 & 1.4 \\ \text { lateral } & 2.0 & 2.0 & 1.4\end{array}$


Table 2. Attitude to control transfer functions.

Rate Command

$$
\begin{aligned}
& \frac{\theta}{\delta_{\theta}}=\frac{M_{\delta_{\theta}}}{s\left(s-M_{Q}\right)} \\
& \frac{\phi}{\delta_{a}}=\frac{L_{\delta_{a}}}{s\left(s-L_{\rho}\right)}
\end{aligned}
$$

Attitude Command

$$
\begin{aligned}
& \frac{\theta}{\delta_{a}}=\frac{M_{\delta_{\theta}}}{s^{2}-M_{q} s-M_{\theta}} \\
& \frac{\phi}{\delta_{a}}=\frac{L_{\delta_{a}}}{s^{2}-L_{p} s-L_{\phi}}
\end{aligned}
$$

\section{Velocity Command}

$$
\begin{aligned}
& \frac{\theta}{\delta_{\theta}}=\frac{M_{\delta_{0}}\left(s-X_{v}\right)}{\left(s+\tau_{v}\right)\left(s^{2}+2 \zeta_{v} \omega_{v} s+\omega_{v}^{2}\right)} \\
& \frac{\phi}{\delta_{a}}=\frac{L_{\delta_{a}}\left(s-Y_{v}\right)}{\left(s+\tau_{v}\right)\left(s^{2}+2 \zeta_{v} \omega_{v} s+\omega_{v}{ }^{2}\right)}
\end{aligned}
$$


Table 3. Suns of Sinusoids for Pad Tracking Task

$$
\begin{aligned}
x_{\text {pad }}= & 5.0\{\sin (.1841 t)+\sin (.3068 t)+\sin (.4909 t)+\sin (.7977 t)+ \\
& 0.1[\sin (1.166 t)+\sin (1.779 t)+\sin (2.823 t)]+ \\
& 0.05[\sin (4.663 t)+\sin (6.934 t)]\} \mathrm{ft} \\
y_{\text {pad }}= & 5.0\{\sin (.2454 t)+\sin (.4295 t)+\sin (.6750 t)+\sin (.9204 t)+ \\
& 0.1[\sin (1.411 t)+\sin (2.270 t)+\sin (3.743 t)]+ \\
& 0.05[\sin (5.706 t)+\sin (7.793 t)]\} \mathrm{ft}
\end{aligned}
$$




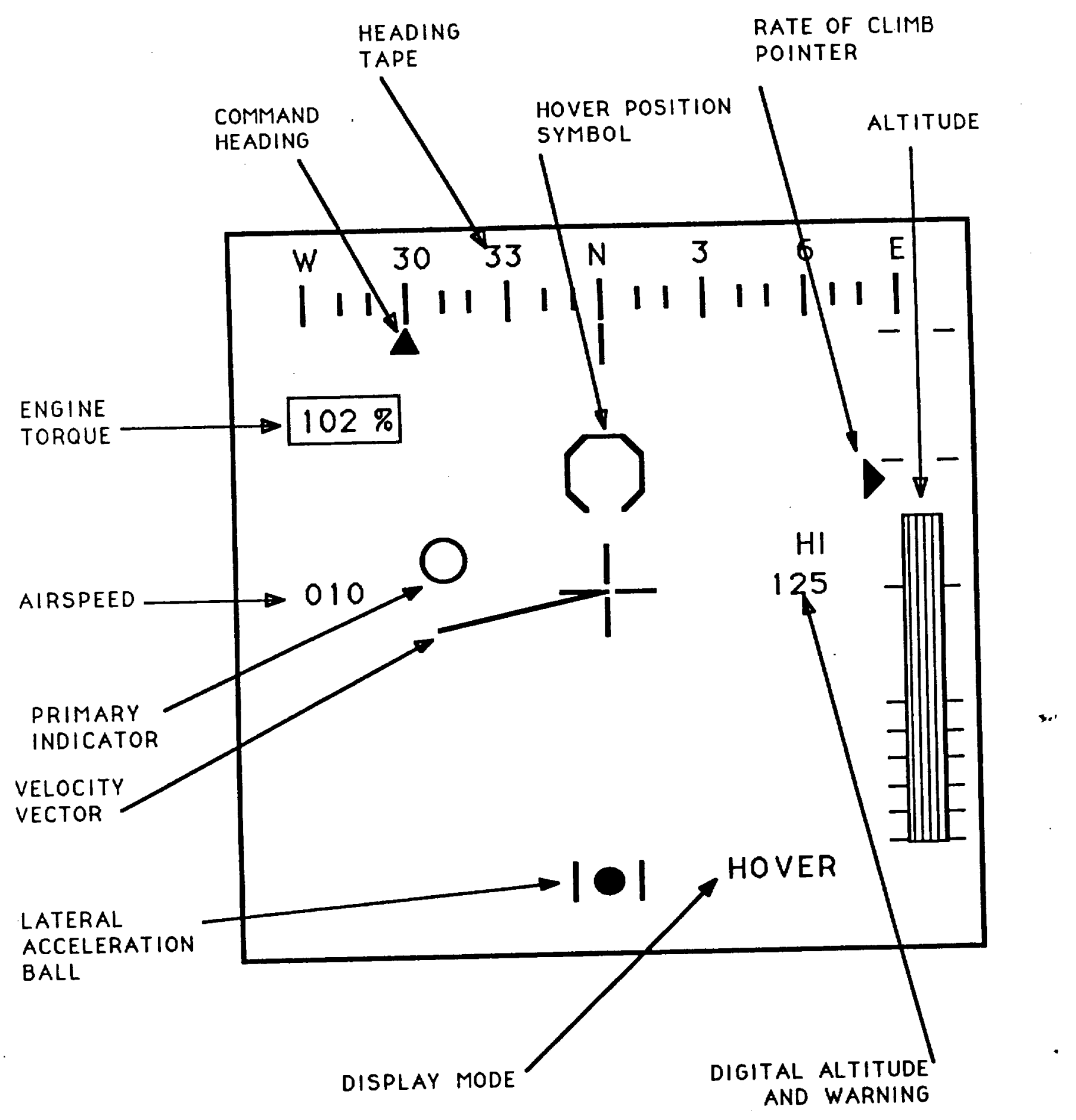

Fig. 1 


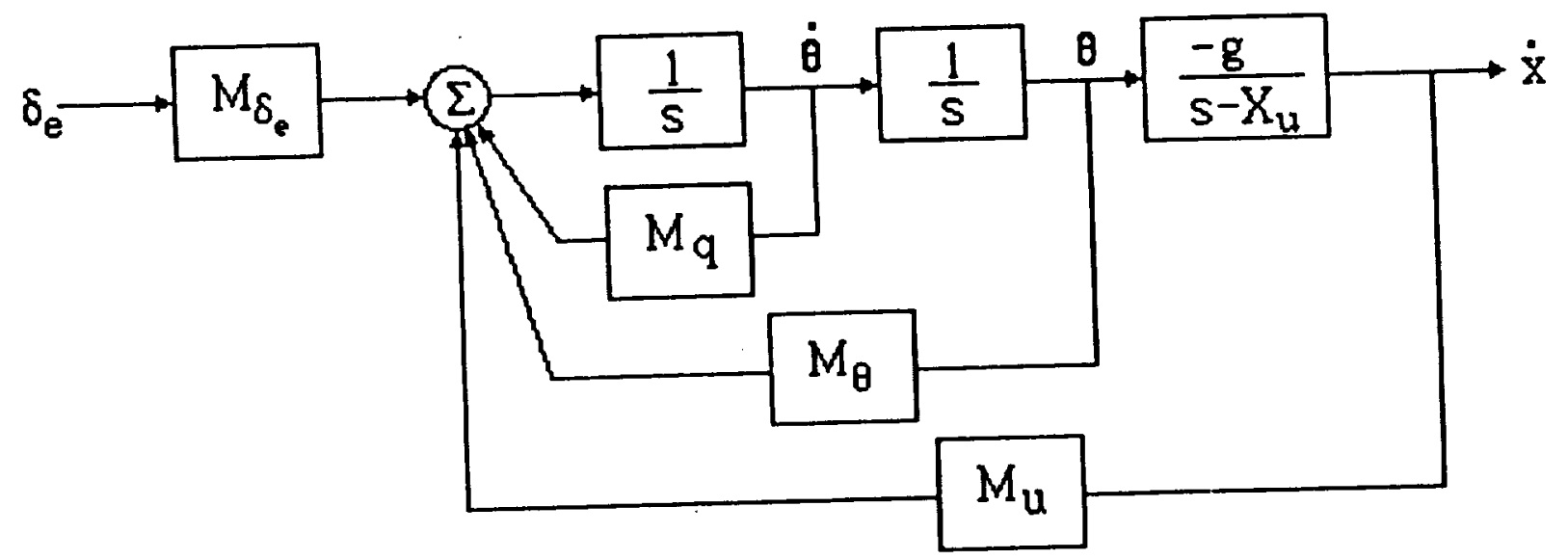

Fig. 2 


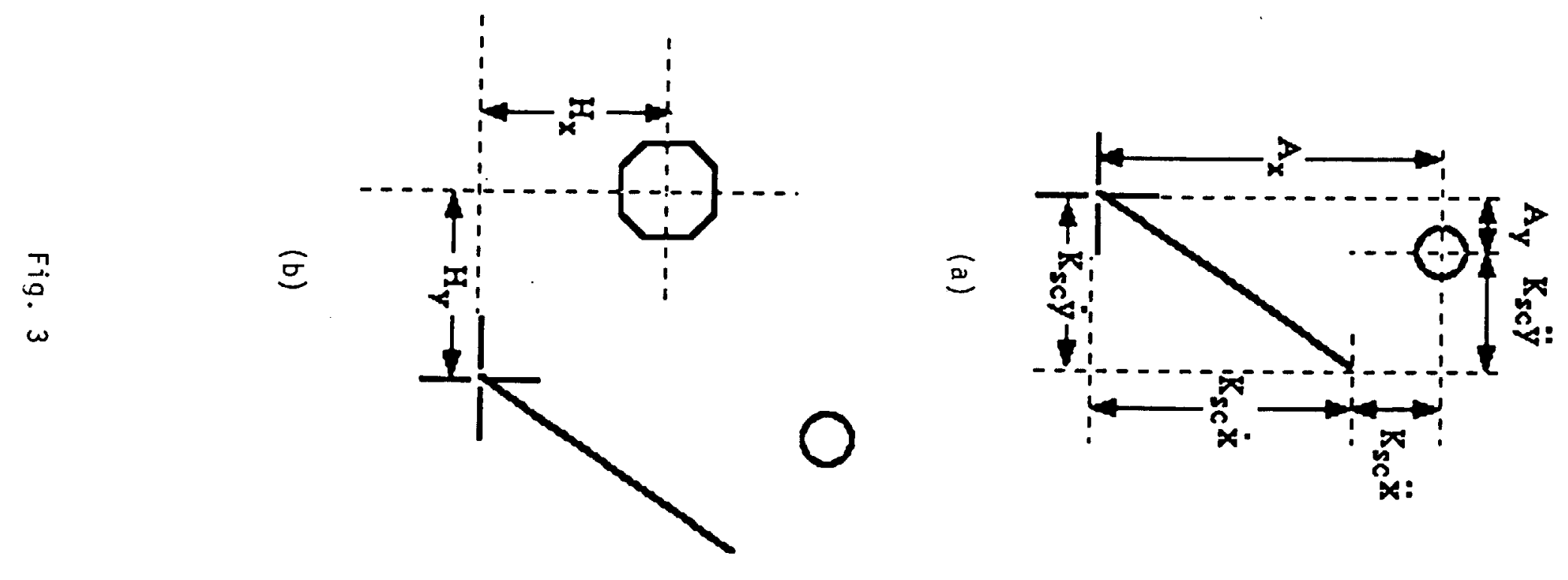




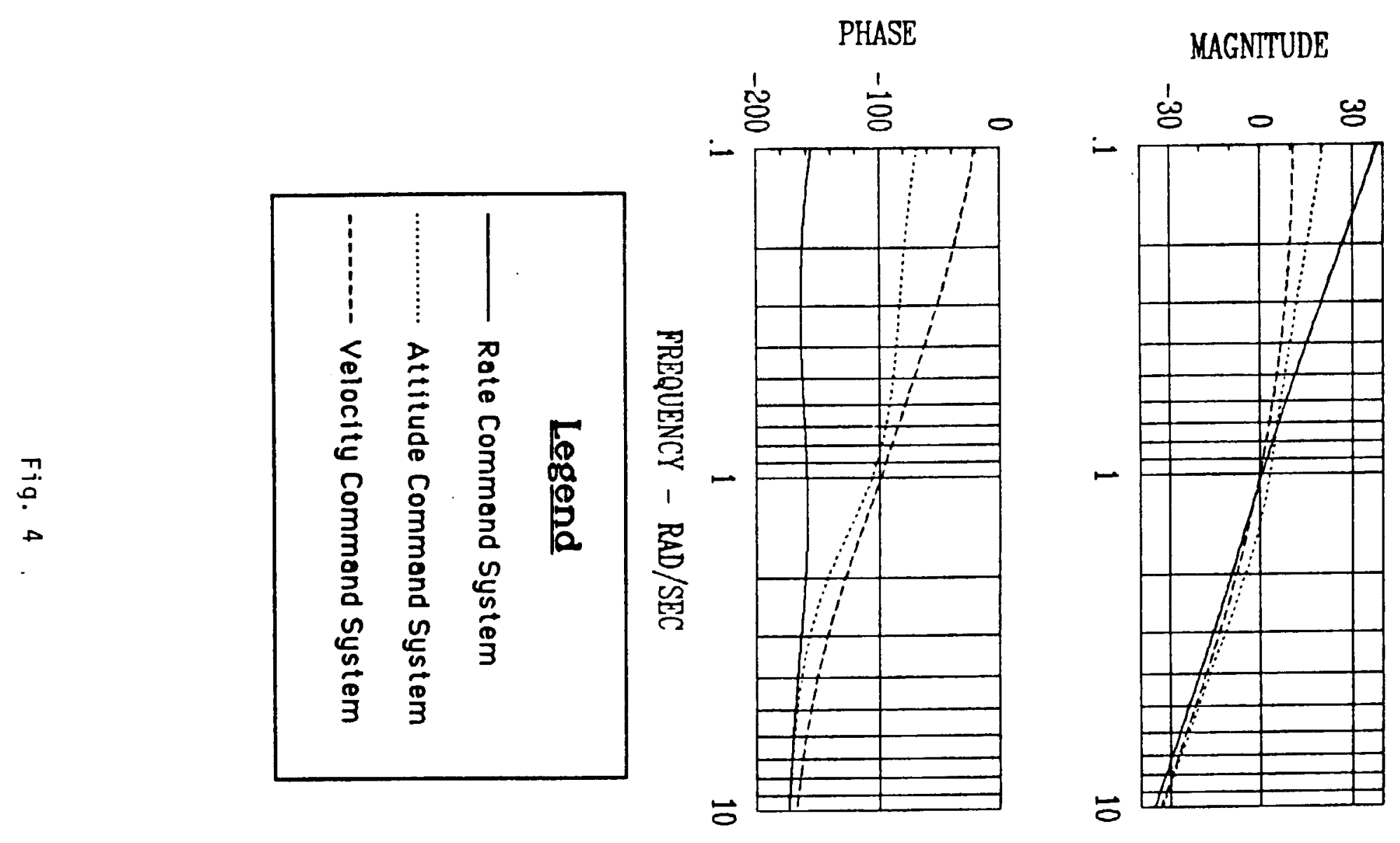



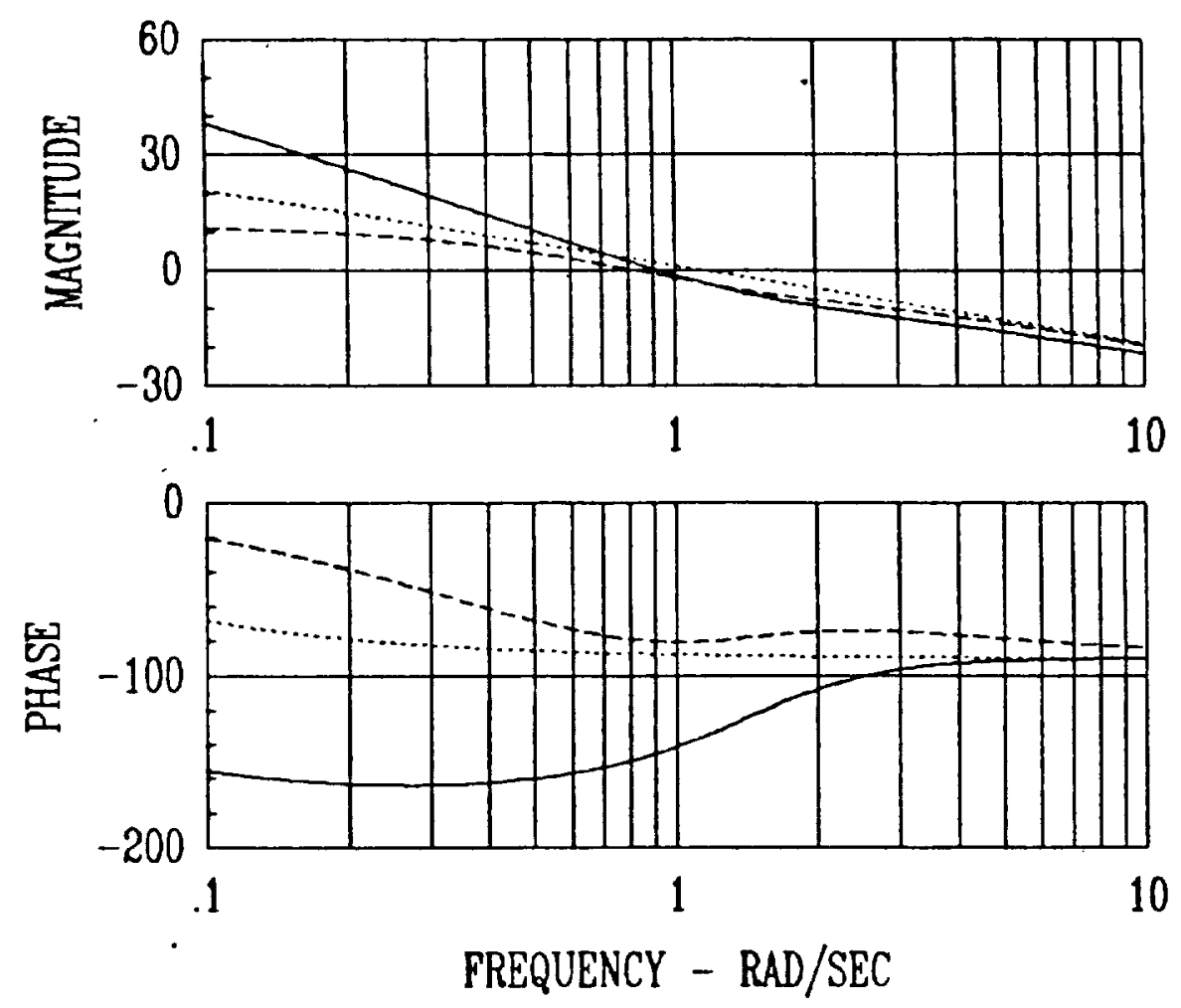

\begin{tabular}{|c|}
\hline Legend \\
Rote Commond System \\
$\ldots \ldots \ldots . .$. Attitude Commend System \\
$\ldots \ldots$ Velocity Commond System
\end{tabular}

Fig. 5 


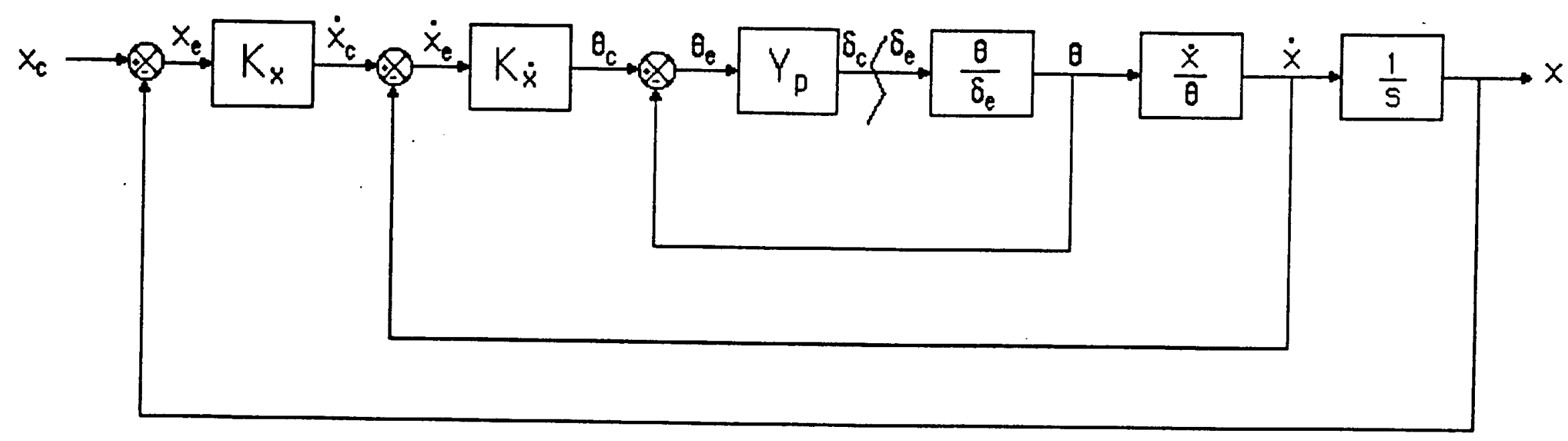

Fig. 6 

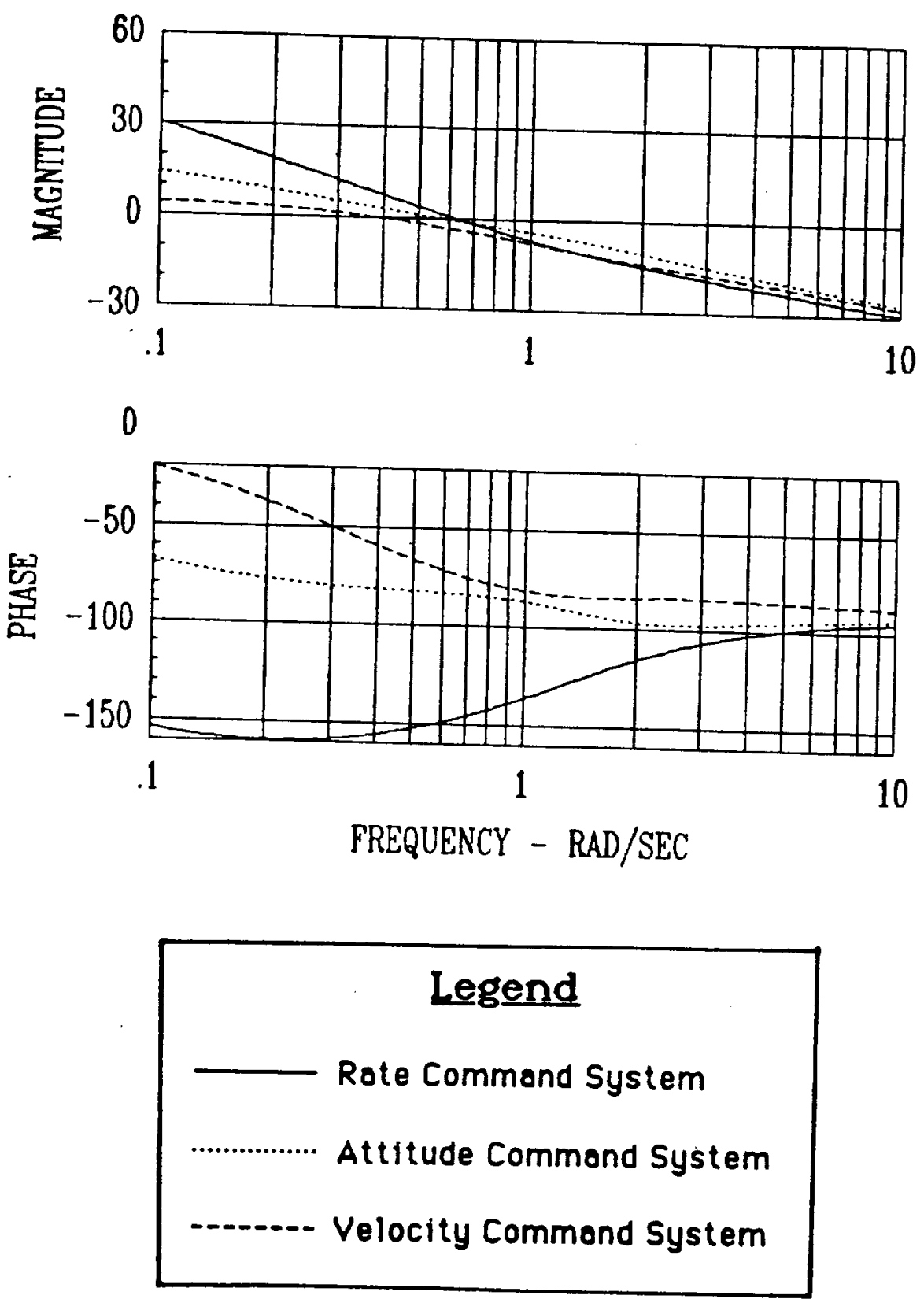

Fig. 7 

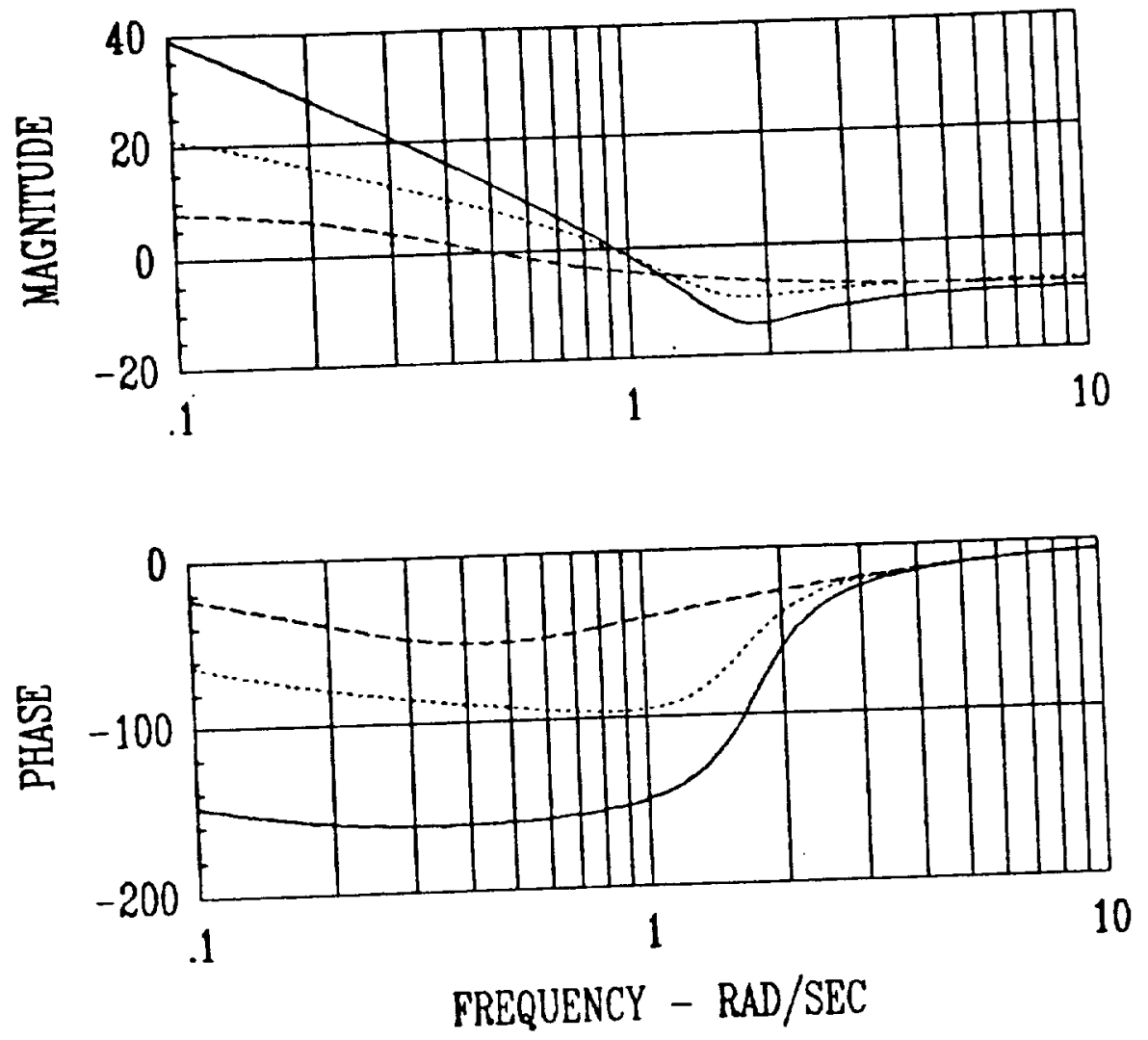

Legend

Rate Command System

Attitude Command System

Velocity Commend System

Fig. 8 


\section{\begin{tabular}{l|l|l} 
RATE & ATTITUDE & VELOCITY
\end{tabular}}

\section{Status}

\begin{tabular}{|l|l|l|l|}
\hline $\mathrm{K}_{\mathrm{SC}}$ & $.256 \mathrm{deg} / \mathrm{m} / \mathrm{sec}$ & $.256 \mathrm{deg} / \mathrm{m} / \mathrm{sec}$ & $.256 \mathrm{deg} / \mathrm{T} / \mathrm{sec}$ \\
\hline
\end{tabular}

\begin{tabular}{|l|l|l|l|}
\hline $\mathrm{K}_{\mathrm{SC}}$ & $.256 \mathrm{deg} / \mathrm{\pi} / \mathrm{sec}$ & $.256 \mathrm{deg} / \mathrm{m} / \mathrm{sec}$ & $.256 \mathrm{deg} / \mathrm{r} / \mathrm{sec}$ \\
\hline
\end{tabular}

\section{Predictor}

\begin{tabular}{l|c|c|c|}
\hline $\mathrm{K}_{\mathrm{SC}}$ & $.256 \mathrm{deg} / \mathrm{n} / \mathrm{sec}$ & $.256 \mathrm{deg} / \mathrm{N} / \mathrm{sec}$ & $.256 \mathrm{deg} / \mathrm{r} / \mathrm{sec}$ \\
\hline$\tau_{\mathrm{P}}$ & $1.0 \mathrm{sec}$ & $1.0 \mathrm{sec}$ & $1.0 \mathrm{sec}$ \\
\hline $\mathrm{X}_{\mathrm{U}}$ & $-.041 / \mathrm{sec}$ & $-.041 / \mathrm{sec}$ & $-.041 / \mathrm{sec}$ \\
\hline
\end{tabular}

\begin{tabular}{l|c|c|c|}
\hline$K_{S C}$ & $.256 \mathrm{deg} / \mathrm{m} / \mathrm{sec}$ & $.256 \mathrm{deg} / \mathrm{m} / \mathrm{sec}$ & $.256 \mathrm{deg} / \mathrm{N} / \mathrm{sec}$ \\
\hline$\tau_{P}$ & $1.0 \mathrm{sec}$ & $1.0 \mathrm{sec}$ & $1.0 \mathrm{sec}$ \\
\hline$Y_{V}$ & $-.121 / \mathrm{sec}$ & $-.121 / \mathrm{sec}$ & $-.121 / \mathrm{sec}$ \\
\hline
\end{tabular}

Fig. 9 


\begin{tabular}{|c|c|c|c|}
\hline & RATE & ATTITUDE & VELOCITY \\
\hline \multicolumn{4}{|c|}{ Command } \\
\hline $\mathrm{K}_{\mathrm{gx}}$ & $-0.1677 \mathrm{deg} / \mathrm{in}$ & $-0.2793 \mathrm{deg} / \mathrm{in}$ & $-0.1853 \mathrm{deg} / \mathrm{in}$ \\
\hline $\mathrm{K}_{\mathrm{P}_{\mathbf{x}}} \cdot$ & $9.573 \mathrm{in} / \mathrm{rad}$ & $6.268 \mathrm{in} / \mathrm{rad}$ & $8.744 \mathrm{in} / \mathrm{rad}$ \\
\hline $\mathrm{K}_{\dot{\mathbf{x}}}$ & $-0.0263 \mathrm{rad} / \mathrm{m} / \mathrm{sec}$ & $-0.0361 \mathrm{rad} / \mathrm{m} / \mathrm{sec}$ & $-0.0380 \mathrm{rad} / \mathrm{m} / \mathrm{sec}$ \\
\hline $\mathrm{k}_{\mathrm{x}}$ & $0.54761 / \mathrm{sec}$ & $0.51731 / \mathrm{sec}$ & $0.5311 / \mathrm{sec}$ \\
\hline Wo & $20.0 \mathrm{sec}$ & $20.0 \mathrm{sec}$ & $20.0 \mathrm{sec}$ \\
\hline$T$ & $0.50 \mathrm{sec}$ & $0.707 \mathrm{sec}$ & $0.707 \mathrm{sec}$ \\
\hline $\mathrm{K}_{\bmod }$ & 1. unmod./2. mod. & 1. unmod./2. mod. & 1. unmod./2. mod. \\
\hline
\end{tabular}

\begin{tabular}{|c|c|c|c|}
\hline $\mathrm{K}_{\mathrm{gy}}$ & $0.1554 \mathrm{deg} / \mathrm{in}$ & $0.2588 \mathrm{deg} / \mathrm{in}$ & $0.2646 \mathrm{deg} / \mathrm{in}$ \\
\hline$R_{P_{y}}$ & $9.573 \mathrm{in} / \mathrm{rad}$ & $6.268 \mathrm{in} / \mathrm{rad}$ & $5.161 \mathrm{in} / \mathrm{rad}$ \\
\hline $\mathrm{K}_{\dot{j}}$ & $0.0265 \mathrm{rad} / \mathrm{m} / \mathrm{sec}$ & $0.0363 \mathrm{rad} / \mathrm{ft} / \mathrm{sec}$ & $0.0399 \mathrm{rad} / \mathrm{r} / \mathrm{sec}$ \\
\hline$k_{\gamma}$ & $0.58641 / \mathrm{sec}$ & $0.555 \mathrm{l} / \mathrm{sec}$ & $0.567 \mathrm{1} / \mathrm{sec}$ \\
\hline$\tau_{\text {wo }}$ & $20.0 \mathrm{sec}$ & $20.0 \mathrm{sec}$ & $20.0 \mathrm{sec}$ \\
\hline$T$ & $0.50 \mathrm{sec}$ & $0.707 \mathrm{sec}$ & $0.707 \mathrm{sec}$ \\
\hline$K_{\text {mod }}$ & 1. unmod./ 2. mod. & 1. unmod./2. mod. & 1. unmod./2. mod. \\
\hline
\end{tabular}




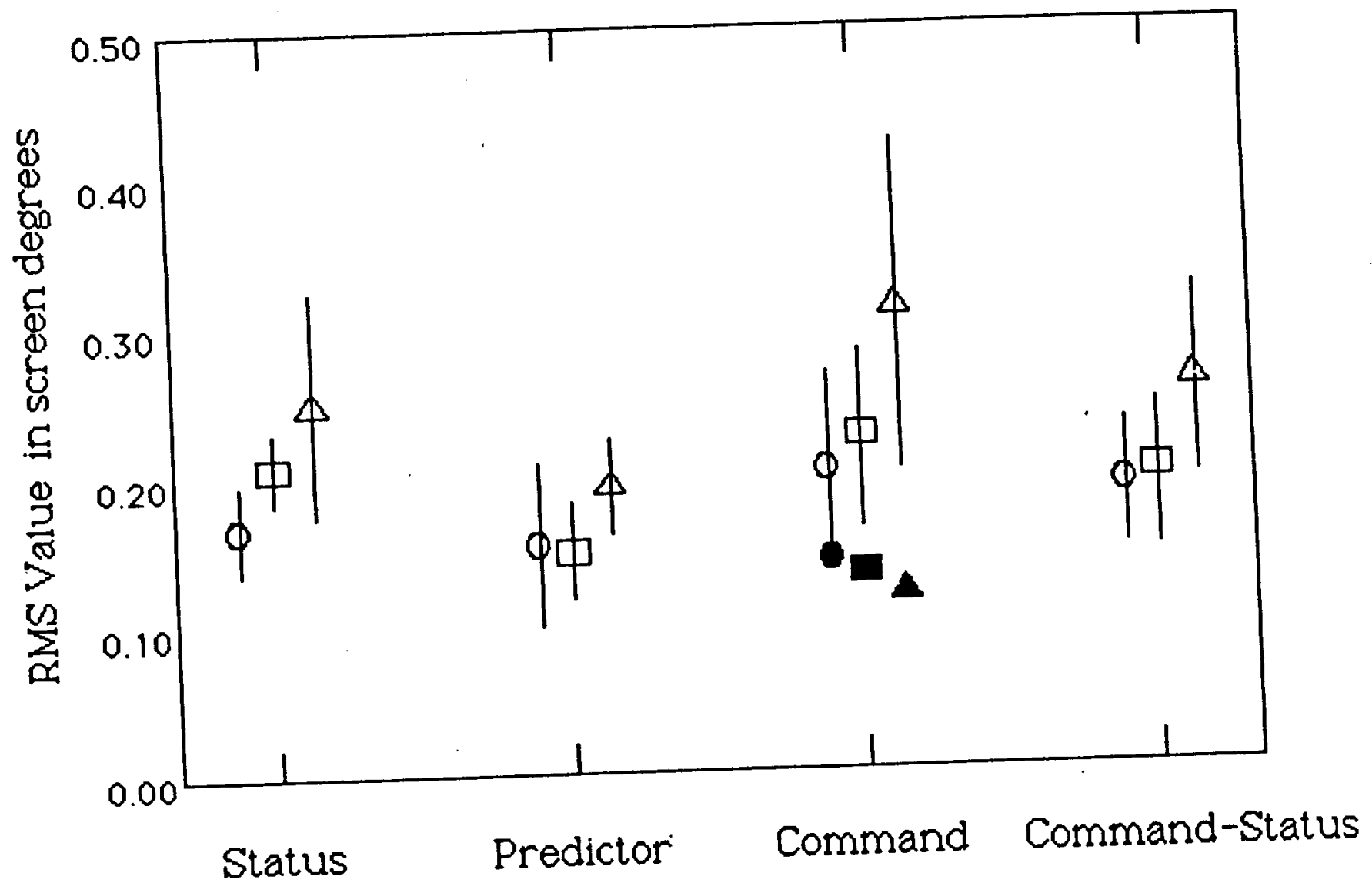

\section{Symbols}

$\triangle \quad$ Rate Command System

$\square \quad$ Attitude Command System

O Velocity Commend System

Fig. 11 


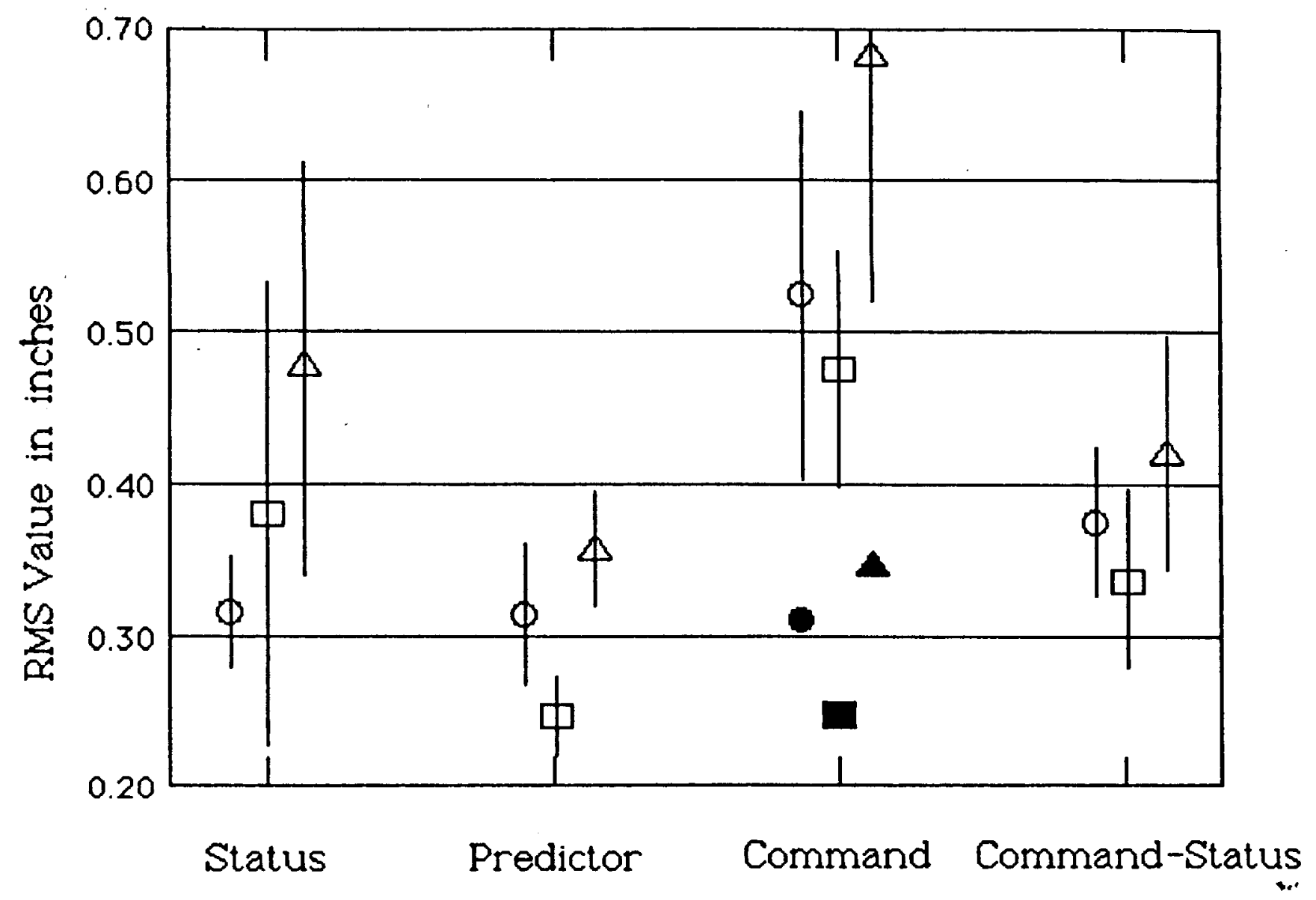

Symbols

$\triangle \quad$ Rote Command System

$\square \quad$ Attitude Command System

O Velocity Command System 


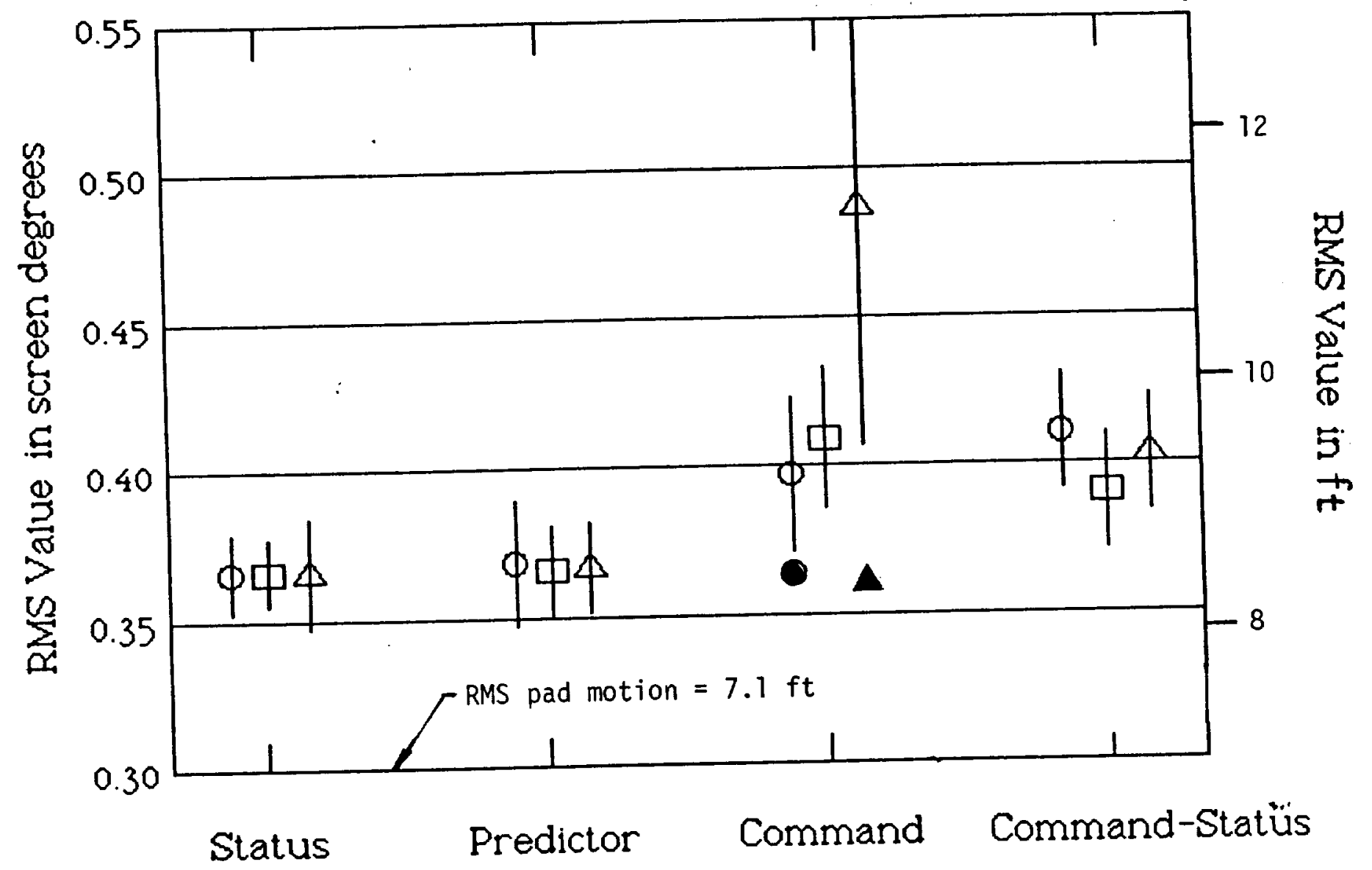

\section{Symbols}

$\triangle \quad$ Rate Command System

$\square \quad$ Attitude Command System

O Velocity Commend System

Fig. 13 


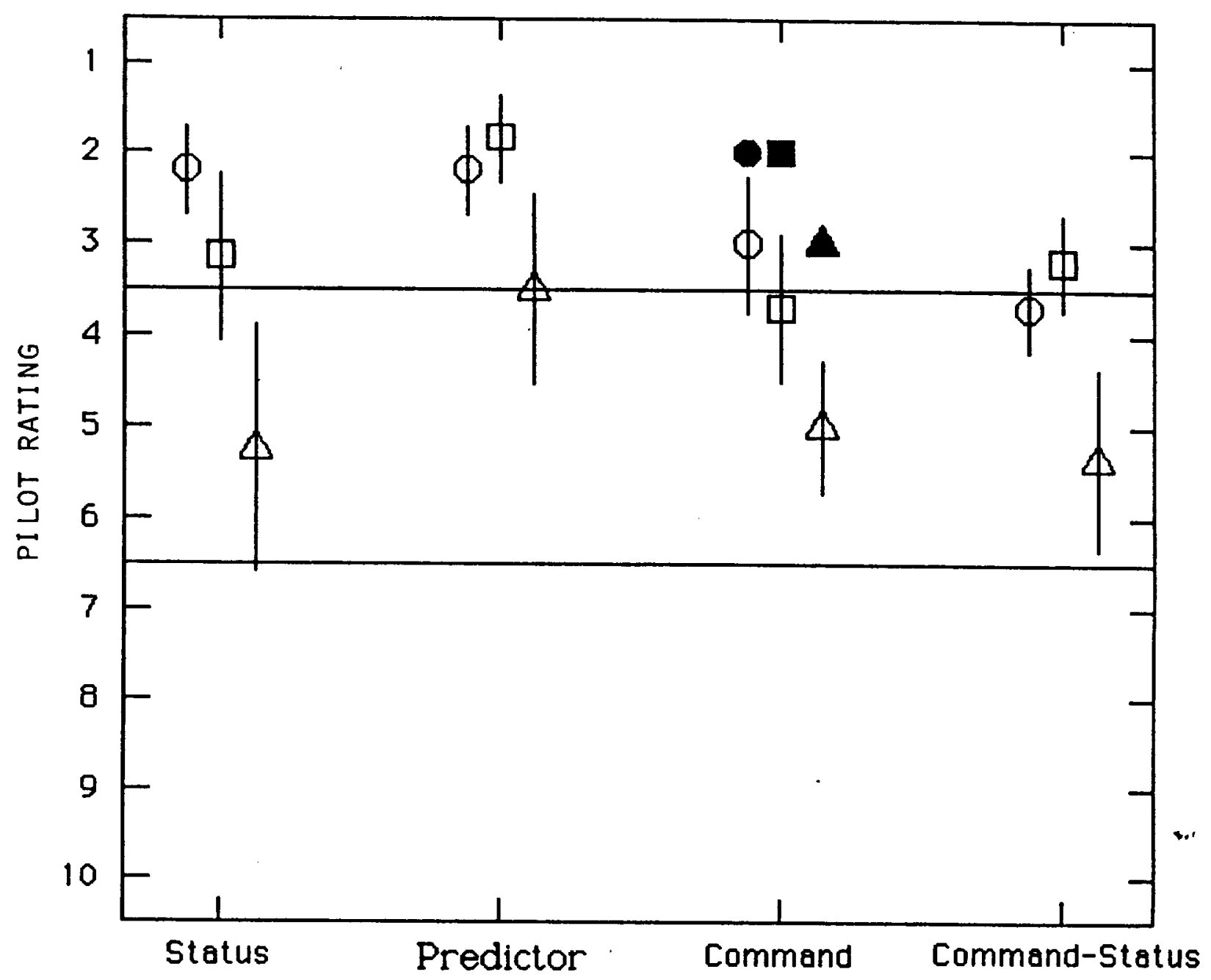

Symbols

$\triangle \quad$ Rote Command System

$\square \quad$ Attitude Command System

O Velocity Command System

Fig. 14 


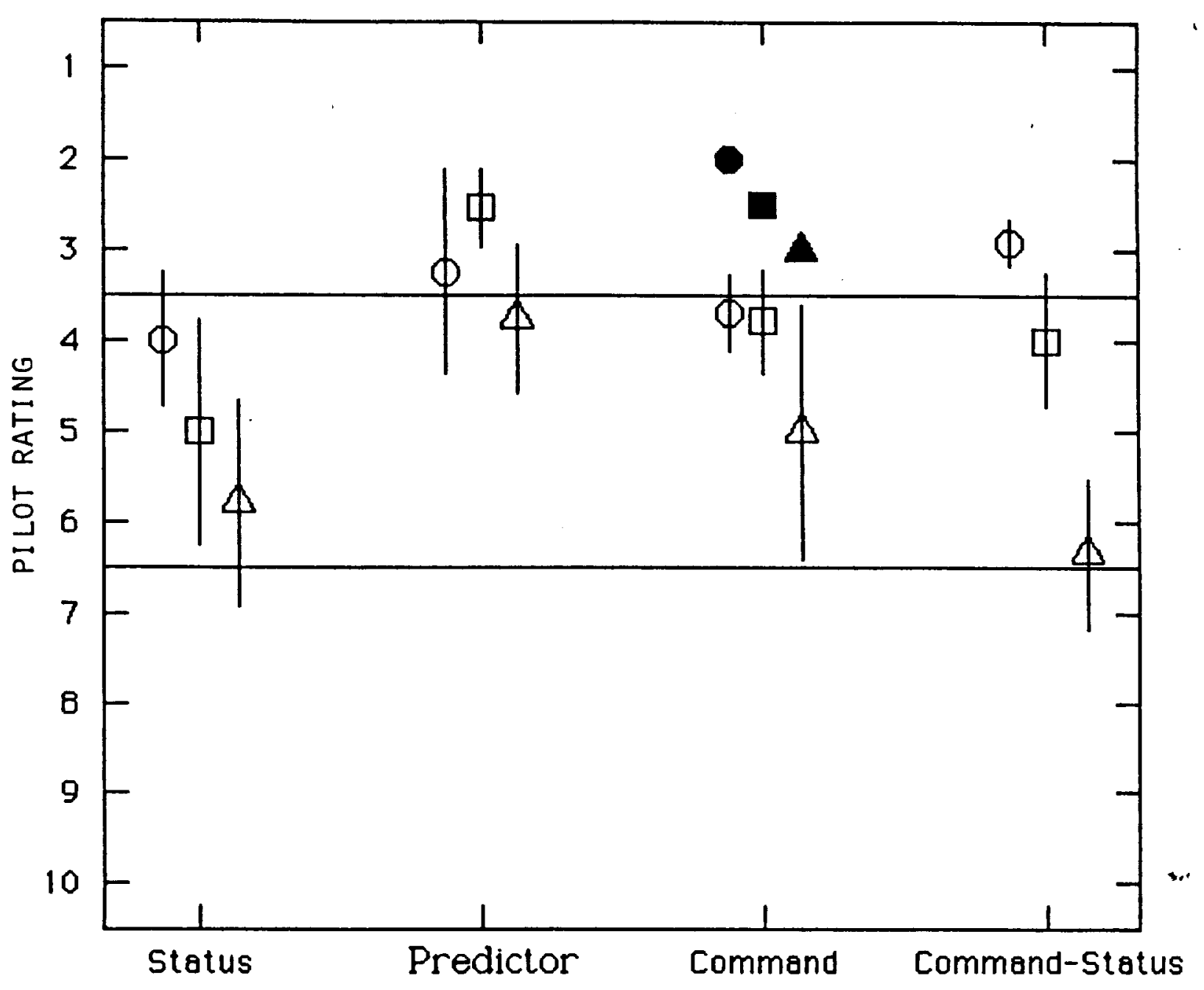

\section{Symbols}

$\triangle \quad$ Rote Command System

$\square \quad$ Attitude Command System

O Velocity Command System

Fig. 15 

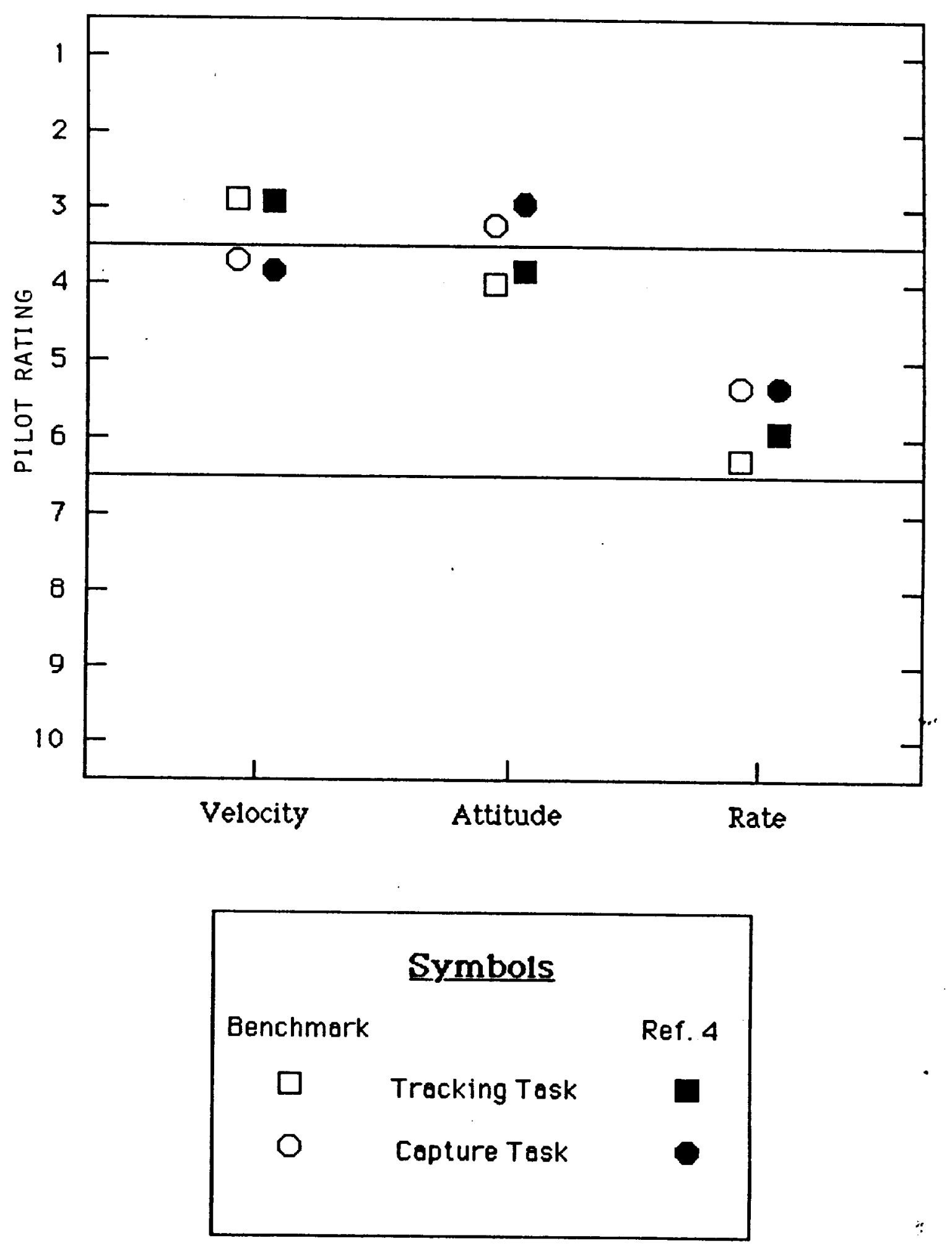